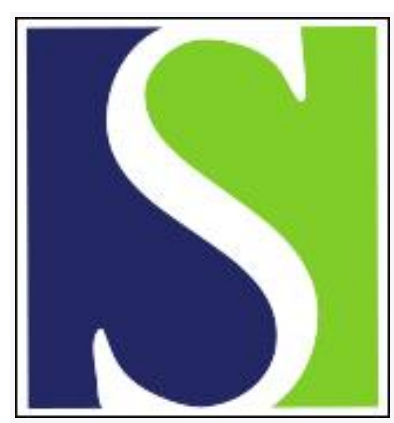

Scand J Work Environ Health 1985;11(5):365-369

https://doi.org/10.5271/sjweh.2211

Issue date: Oct 1985

Exposure to cutting oils and its relation to skin tumors and premalignant skin lesions on the hands and forearms.

by Jarvholm B, Fast $K$, Lavenius B, Tomsic $P$

This article in PubMed: www.ncbi.nlm.nih.gov/pubmed/4071002

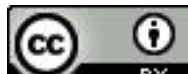




\title{
Exposure to cutting oils and its relation to skin tumors and premalignant skin lesions on the hands and forearms
}

\author{
by Bengt Järvholm, MD, ${ }^{1}$ Kristian Fast, MD, ${ }^{2}$ Bengt Lavenius, MD, ${ }^{2}$ Paulus Tomsic, $M D^{2}$
}

\begin{abstract}
JÄRVHOLM B, FAST K, LAVENIUS B, TOMSIC P. Exposure to cutting oils and its relation to skin tumors and premalignant skin lesions on the hands and forearms. Scand J Work Environ Health 11 (1985) 365-369. In a cohort study the incidence of skin tumors on the hands and forearms of 682 turners exposed to cutting oils was compared to the incidence of the general male population and of office workers. Among the 682 turners, five premalignant squamous cell tumors and eight keratoacanthomas were found between 1960 and 1980 . Five of this total of 13 turners with primary skin tumors had another skin tumor as well. Among the 682 men there were four cases of scrotal cancer. Among the 375 office workers examined, no malignant or premalignant tumors or keratoacanthomas were found on the hands or forearms. No primary skin tumors were found among the turners after 1975 , when the acid-refined mineral oils were replaced by solvent-refined oils containing a far lower concentration of polyaromatic hydrocarbons, which are probably the cancerogenic agent in the oils. The study shows a greatly increased risk of skin tumors on the hands and forearms of workers exposed to acid-refined mineral oils. Individual susceptibility also seems to be indicated.
\end{abstract}

Key terms: keratoacanthoma, mineral oils, oil acne, polyaromatic hydrocarbons, precancerosis, secondary tumors.

Long-term exposure to mineral oil is a well-known cause of skin cancer on the scrotum (14). However, the association between long-term exposure to cutting oils and skin tumors on other sites is far less clearly established. Cruickshank \& Gourevitch (4) described 44 cases of skin cancer on the hands and forearms of men in the Birmingham area between 1941 and 1950. Thirty-seven of these individuals were available for interviews, and 18 reported a history of oil exposure. Mastromatteo (12) described five cases of skin cancer on the hands and forearms of workers in a mechanical engineering plant in 1955. Compared to national incidence rates, this observation suggested a possible relationship between the occurrence of squamous cell carcinoma and long occupation as a machine operator. Studies of workers exposed to oil mist have not revealed an increased incidence of skin cancer on the hands or forearms $(5,6,8)$.

Mortality from squamous cell skin tumors is low. Cruickshank \& Gourevitch (4) have estimated the case mortality from squamous cell carcinomas on the hands and forearms to be $12 \%$. It is therefore difficult to detect an increased incidence of squamous cell skin carcinoma in mortality studies. Some of the tumors may even be treated as premalignant lesions, and subsequent morbidity studies based on cancer registrations may thus underestimate the risk.

1 Department of Occupational Medicine, University of Gö-
teborg, Sahigren Hospital, Göteborg, Sweden.
2 Health Department, AB SKF, S-415 50 Göteborg, Sweden.

Reprint requests to: Dr B Järvholm, Department of Occupational Medicine, Sahlgren Hospital, St Sigfridsgatan 85 , S-412 66 Göteborg, Sweden.
Ghadially et al (7) reviewed 238 cases of keratoacantoma in Sheffield between 1954 and 1959. They could not find any evidence of an association between oil exposure and keratoacanthomas, although they did find an association between this disease and exposure to soot and tar.

The objective of our study was to investigate the risk for malignant and premalignant skin lesions and keratoacantomas on the hands and forearms of workers exposed to cutting oils. The study was designed as a cohort investigation in which the incidence of these lesions among workers exposed to cutting oil is compared to that of office workers and that of the total male population of the same city.

\section{Subjects and methods}

The study was performed in an industry producing bearing rings. The company was founded in 1907 and today employs about 2500 blue-collar workers and 1000 white-collar workers. It is situated in Göteborg, Sweden, a city with about 500000 inhabitants.

In the 1940 s and 1950 s a few cases of skin cancer on the scrotum were discovered among workers in the lathe departments. In 1958 a dermatologist was hired to examine the turners regularly in order to detect scrotal cancer at an early stage. This screening was performed three or four times a year. The same dermatologist (KF) has made all the examinations since 1958. Almost every turner employed in that department participated in the examinations, which were made during the workday. The results were noted on special lists that also contained information for each individual as to the occurrence of oil acne on the 
Table 1. Frequency of total exposure time through 31 December 1980 for 682 men exposed to cutting oils.

\begin{tabular}{lcc}
\hline $\begin{array}{l}\text { Exposure time } \\
\text { (years) }\end{array}$ & $\begin{array}{c}\text { Number } \\
\text { of men }\end{array}$ & $\begin{array}{c}\text { Frequency } \\
(\%)\end{array}$ \\
\hline $1-4$ & 367 & 54 \\
$5-9$ & 111 & 16 \\
$10-14$ & 49 & 7 \\
$15-19$ & 40 & 6 \\
$20-24$ & 33 & 5 \\
$25-29$ & 26 & 4 \\
$\geq 30$ & 56 & 8 \\
\hline Total & 682 & 100 \\
\hline
\end{tabular}

forearms and the number of years each person had worked in the lathe department.

Between 1 January 1960 and 31 December 1980 these lists contained the names of 685 workers (excluding foremen), 682 of whom could be identified.

This study was designed as a cohort study in which the incidences of skin lesions on men exposed to oil and those of reference groups are compared. The 682 lathe operators constituted the exposed group. Their total exposure time, that is, their exposure time through 31 December 1980, is described in table 1.

The national cancer register was studied to find cases of malignant skin tumors among the turners. This incidence was compared to that of the male population of the same city. The expected incidence was calculated by multiplying the gender-specific incidence rates by the number of person-years; stratifying for calendar year, age (5-year age groups), and exposure time or latency period; and summarizing across the cohort. The latency period was defined as the time having elapsed since the date of the individual's employment in the turning department. Person-years were calculated through 31 December 1980 or to the date of death or emigration, if it occurred before 1980. The incidence rates for the city of Göteborg were provided by the Cancer Registry.

There is no official register of premalignant skin lesions or keratoacanthomas. We used health records kept by the health care department of the company to establish the incidence among the turners. The expected incidences were estimated from interviews of office workers and examinations of statistics from the register of the Department of Pathology in Göteborg. The different procedures used for this process follow.

This industry has had a health care department since its establishment. Health records could be located for 544 of the 682 men. There were no compulsory examinations at the health care department, and the other 138 men had probably never used its services. No health records have been destroyed. One hundred and twenty $(87 \%)$ of the 138 men had exposure times of less than 10 years. The health records were reviewed for the occurrence of skin lesions, interest being focused on malignant skin tumors, premalignant skin lesions (eg, Bowen's disease, actinic keratosis, dys- plasia), and keratoacanthoma. Only biopsied skin tumors verified by a pathologist's examination were accepted.

In all, 400 office workers in the same industry were selected as a reference group. They were a random sample of all office workers employed by the company in 1983, in the lower range of the salary scale. Office workers are classified by salary on a scale from 1 through 8 , where 1 is the highest level. To obtain reasonably similar economic backgrounds among the men in the exposed and reference groups, only men from levels 4 through 8 were included. A questionnaire was sent to the 400 office workers. It contained the question "Have you had any skin tumors?" and, if the answer was yes, a request to state the location of the tumor, date of treatment, and the physician's name and address. Three hundred and seventy-five of the office workers answered the questionnaire $(94 \%$ ).

The Department of Pathology of the University of Göteborg has a computerized register of diagnoses made since late 1982. The Department makes more than $95 \%$ of the pathology examinations in the region. All cases of premalignant skin tumors and keratoacanthomas diagnosed in 1983 were retrieved from this register. The diagnoses are classified according to the SNOMed index (3) and the following tumors were considered (SNOMed number in parentheses): atypia UNS (M69700), senile keratosis (actinic keratosis; M72850), keratoacanthoma (M72860), dysplasia (M74000), cancer in situ (M80702).

The differences between the observed and expected incidences were tested according to a Poisson distribution. The figures for the p-values describe two-tailed tests (1).

\section{Exposure}

Straight mineral oils have always been used in the turning department. Until 1975 acid-refined oils were used. Then there was a change to solvent-refined oils. Sulfur has been added as an extreme pressure agent in concentrations of less than $1 \%$. Until 1950 about $10 \%$ animal or vegetable oils was added.

There are always difficulties involved in measuring exposure to the skin. The skin is mostly exposed through splashing and, to a far smaller extent, through oil mist. The level of oil mist in this plant has earlier been assessed and was about $5 \mathrm{mg} / \mathrm{m}^{3}$ or more before 1965. It is about $2 \mathrm{mg} / \mathrm{m}^{3}$ today. Oil acne may occur if the skin is heavily exposed to mineral oils. We have used the prevalence of oil acne on the forearm to measure exposure to the skin. The occurrence of oil acne was registered twice to four times a year by the same physician (KF) at the medical examinations. If the man had acne in any of the examinations during a calender year, he was noted in the examination as having oil acne that year. The prevalence of oil acne between 1960 and 1980 is shown in figure 1 . The major 


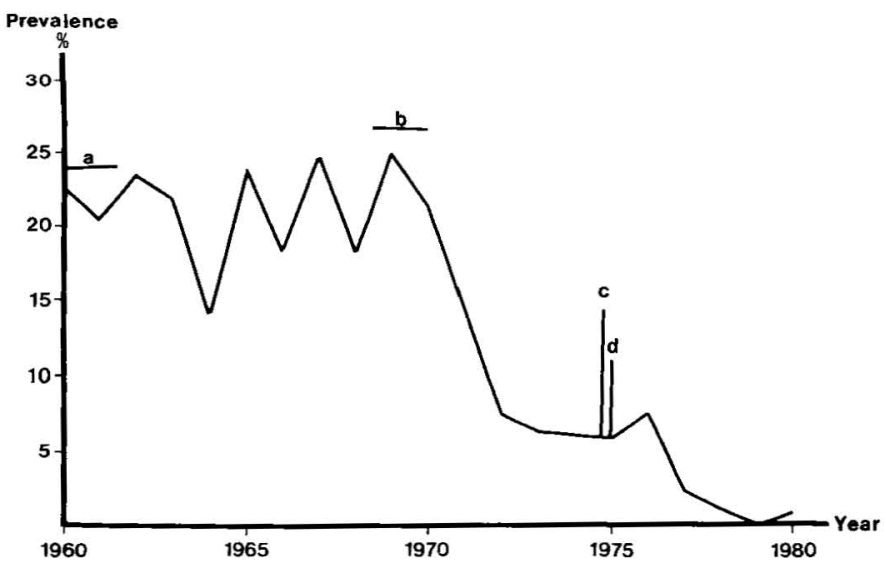

Figure 1. Prevalence of oil acne on the forearms of turners. The letters show major changes in the work environment. $(a=$ automatic removal of rings, $b=$ new turning method with less tool-setting, $c=$ free supply of workclothes, $\mathrm{d}=$ change to solvent-refined oil)

changes in the work environment that may have influenced the prevalence are also marked.

In the early 1960s a process was developed for removing the pieces of metal from the lathes mechanically instead of manually. This occurrence did not particularly influence the prevalence of oil acne. The change made in the turning method in the late 1960s, however, reduced the prevalence dramatically. With this new method, the piece of metal was turned in one operation, which greatly reduced the need for toolsetting. The turning machines were unchanged throughout the 1960s and 1970s, and there have only been minor changes in the splash guards. However, the splash guards could be used much more effectively once there was less need of tool-setting, beginning in the late 1960s. The change to solvent-refined oils and the introduction of workclothes supplied free of charge (ie, T-shirts and trousers) also coincides with a reduction in the prevalence of oil acne. The washing facilities have remained unaltered throughout this time period.

\section{Results}

Five of the 682 exposed men were reported as having malignant skin tumors in the cancer register between 1960 and 1980 (exclusive of basaliomas). All cases were squamous cell carcinoma (no melanoma). Four were situated on the scrotum and one on the face. The exposure time of these men was $13,19,33,39$, and 13 years, respectively. Compared to the male population of the same city 0.3 cases were expected (melanomas excluded) among men with at least five years of exposure time $(p<0.001)$. A total of 24 malignant tumors were reported to the registry between 1960 and 1980 . One man had two tumors at different sites. Twentytwo of these cases occurred after a latency period of at least 10 years, the expected incidence was 29.2 on the basis of data on males in the same city as a reference group and an allowance for at least a 10-year latency period (5 901 person-years) (not significant).
Except for cases of skin cancer the sites varied greatly, with just one to three cases at each site. This finding means that a separate analysis by site would not be rewarding.

In the health records there were 13 patients with primary skin lesions on the hands and forearms, eight cases of keratoacanthoma and five cases of premalignant lesions (table 2). All were verified through biopsies. Two more keratoacanthomas on the hands were mentioned in the records, but there were no examined biopsies. The saved biopsies were reviewed in 1983 .

All the cases had rather long exposure times before the occurrence of the lesions. In five cases secondary primary skin lesions also developed, two of which were cases of malignant squamous cell carcinoma on the scrotum. One of the 13 patients also developed a lung tumor.

Five cases of premalignant skin tumors or keratoacanthomas situated on the hands or forearms of males 20-69 years of age were registered in 1983 in the computerized register of the Department of Pathology. The cases in the register occurred in a population of about 156000 males $20-69$ years of age. The number of cases was too few to make a reliable estimate of the expected number for the turners exposed to oil, but it is obvious that there is an increased incidence of these lesions among the workers exposed to oil. No premalignant skin lesions or keratoacanthomas situated on the hands or forearms were reported among the office workers.

\section{Discussion}

When we began this study, we thought it might be the case that skin lesions on the hands or forearms were treated at a premalignant stage, and this hypothesis has been confirmed. There were five premalignant lesions on the hands or forearms among the turners, but none were registered in the cancer register. (It is not compulsory to report premalignant lesions to the Swedish Cancer Registry.) This finding might explain 
Table 2. Men with premalignant skin lesions or keratoacanthomas on their hands or forearms.

\begin{tabular}{|c|c|c|c|c|c|}
\hline Diagnosis & Year & $\begin{array}{c}\text { Age } \\
\text { (years) }\end{array}$ & $\begin{array}{l}\text { Exposure } \\
\text { time } \\
\text { (years) }\end{array}$ & $\begin{array}{l}\text { Oil acne } \\
\text { on forearms }\end{array}$ & Secondary lesions \\
\hline \multicolumn{6}{|l|}{ Senile keratosis } \\
\hline Right forearm & 1961 & 63 & 36 & No & \multirow[b]{5}{*}{$\begin{array}{l}\text { Senile keratosis both forearms } 1977 \text {, } \\
\text { basalioma right leg } 1978\end{array}$} \\
\hline Left forearm & 1968 & 61 & 34 & No & \\
\hline Right forearm & 1970 & 56 & 22 & & \\
\hline Left forearm & 1970 & 57 & 33 & Yes (2) & \\
\hline Left forearm & 1973 & 53 & 28 & Yes (2) & \\
\hline \multicolumn{6}{|l|}{ Keratoachantoma } \\
\hline Right hand & 1960 & 58 & 26 & No & \multirow[b]{2}{*}{$\begin{array}{l}\text { Scrotal cancer 1967, keratoachantoma } \\
\text { right forearm 1973, keratoachantoma } \\
\text { on the face } 1974,1975\end{array}$} \\
\hline Right forearm & 1963 & 57 & 29 & No & \\
\hline Right forearm & 1965 & 66 & 40 & No & \\
\hline Right forearm & 1971 & 55 & 34 & & Lung cancer 1978 \\
\hline Right hand & 1972 & 50 & 15 & Yes (2) & Basalioma on the face 1978 \\
\hline Right forearm & 1973 & 58 & 29 & Yes (5) & Keratoachantoma on the face 1975 \\
\hline Left forearm & 1974 & 42 & 18 & Yes (5) & \\
\hline Right hand & 1975 & 48 & 18 & Yes (3) & \\
\hline
\end{tabular}

a No = no oil acne in any of the examinations 1960-1980; yes = oil acne in some of the examinations 1960-1980; values in parentheses show how many calendar years oil acne occurred.

why the association between tumors on these sites and mineral oil exposure is difficult to establish.

The 13 cases of premalignant skin lesions or keratoacanthomas found in this study are only a minimum finding. Some persons may have visited other doctors for skin lesions and consequently not have been revealed in this study. However, the treatment at the company was free of charge, and the workers interviewed believed that almost all workers went to the company health care department if they had a skin lesion.

A comparison with the data from the computer register of the Department of Pathology makes it evident that there was an increased incidence of skin lesions on the hands and forearms of men exposed to oil. A possible bias from changes in diagnosing practices was excluded by a reexamination of the biopsies. The office workers reported no premalignant skin lesion or keratoacanthomas on their hands or forearms. Another possible source of error might be underreporting among these men. However, we reviewed all records where any skin desease on the questionnaire was mentioned $(N=69)$. Although there might have been some underreporting, it would hardly account for most of the difference. Among the office workers skin lesions not treated by the health care department could have been reported in the questionnaires. This possibility would mean that the risk among office workers compared to men exposed to oil was overestimated. Another possible bias is the health surveillance of workers exposed to oil. Office workers may not have sought treatment for their premalignant skin lesions or keratoacanthomas, but this is improbable. We think that most people with easy access to medical care will see a doctor if they have such a lesion.

Thus there was found to be a greatly increased risk of premalignant skin lesions and keratoacanthomas among workers with long exposure times to oil. At least some 15 years of exposure seem to be necessary for these lesions to develop (table 2). Thirteen (8\%) of the 155 men with at least 15 years of exposure had such lesions.

No primary cases were found after 1975, a date which coincides with a sharp decrease in oil acne and a change to solvent-refined mineral oils that took place at that time. Solvent refining reduces the content of polycyclic aromatic hydrocarbons (PAH), which are probably the major carcinogenic compounds in the oil. It is well known from animal experiments that the carcinogenic potency of acid-refined oils is great compared to that of solvent-refined oils $(2,9)$. These observations agree well with our findings.

Today, solvent-refined mineral oils are used in most cutting oils. New PAH may be formed because of high temperatures and pressures but not nearly to as great an extent in cutting oils as in other types of oil. In motor oils or quenching oils there may be far more than a tenfold increase of PAH (13). In cutting oils, the increase of benzo(a)pyrene is about twofold $(11,13)$.

In 1975 workclothes began to be supplied at the plant free of charge, and this procedure may have decreased exposure to cutting oils. Instead of the long sleeve shirts which were used by some of the workers, short sleeve $\mathrm{T}$-shirts began to be used. This change facilitated the cleaning of the forearms. The use of highly refined (solvent-refined) mineral oils and good work practices may therefore considerably decrease the risk of premalignant skin lesions and keratoacanthomas.

Some individuals seem to be especially prone to oilinduced skin lesions, as 6 of the 13 men with primary skin lesions on the hands or forearms also had other lesions, generally elsewhere on the skin. Some of these lesions developed after the change to solvent-refined 
oils. The production process was uniform with similar or identical lathe machines, and we do not consider differences in exposure to be a completely satisfactory explanation for the much higher risk for some individuals. Mastromatteo (12) found that three of five men who were exposed to oil and had squamous cell carcinoma on the hands or forearms developed other tumors. The theory of increased susceptibility of some individuals is also supported by the findings of Kipling \& Waldron (10). They found an increased incidence of tumors of the skin, lung, and stomach in 282 cases of primary scrotal cancer, as compared to the general population. However, no increased incidence of lung cancer has been found in recently published studies of workers exposed to oil mist $(5,8)$. The cause of this individual susceptibility is unknown, but differences in the ability to induce aryl hydrocarbon hydroxylase has been suggested, although it has not been proved in man (10). Differences in the ability to carry out the repair of deoxyribonucleic acid (DNA) may be an alternative explanation. This susceptibility may be primary or acquired before, during, or after the first skin lesion. As there is a strong indication of individual susceptibility, a person exposed to oil who has a malignant or a premalignant skin lesion or a keratoachantoma should receive a recommendation to change to a job not requiring exposure to oil.

In summary, this study shows that workers exposed to oil run an increased risk of developing premalignant skin lesions and keratoachantomas on the hands and forearms and that there seems to be individual susceptibility to develop such lesions.

\section{Acknowledgments}

We thank Dr $\mathrm{H}$ Gisslen for reexamining the biopsies and for valuable discussions, and associate professor J Säve-Söderbergh, MD, for providing data from the register of the Department of Pathology. We also thank Ms M Dahlsten, Ms K Johanson, and Ms I Claesson for their skillful assistance with the data collection.
This work was supported by the Swedish Work Environment Fund.

\section{References}

1. Bailar JC, Ederer F. Significance factors for the ratio of a Poisson variable to its expectation. Biometrics 20 (1964) 639-643.

2. Bingham E, Horton $W$, Tye R. The carcinogenic potency of certain oils. Arch Environ Health 10 (1965) 449-451.

3. Cote RA. Systematized nomenclature of medicine (SNOMed). College of American Pathologists, Skoki, IL 1979.

4. Cruickshank CND, Gourevitch A. Skin cancer of the hand and forearm. Br J Ind Med 9 (1952) 74-79.

5. Decoufle P. Further analysis of cancer mortality patterns among workers exposed to cutting-oil mist. J Natl Cancer Inst 61 (1978) 1025-1030.

6. Ely TS, Pedley SF, Hearne FT, Stille WT. A study of mortality symptoms and respiratory function in humans occupationally exposed to cutting oil mist. J Occup Med 12 (1970) 253-261.

7. Ghadially FN, Barton BW, Kerridge DF. The etiology of keratoacanthoma. Cancer 16 (1963) 603-611.

8. Järvholm B, Lillienberg L, Sällsten G, Thiringer G, Axelson $\mathrm{O}$. Cancer morbidity among men exposed to oil mist in the metal industry. J Occup Med 23 (1981) 333-337.

9. Kane ML, Ladov EN, Holdsworth CE, Weaver NK. Toxicological characteristics of refinery streams used to manufacture lubricating oils. Am J Ind Med 5 (1984) $183-200$.

10. Kipling MD, Waldron HA. Polycyclic aromatic hydrocarbons in mineral oil, tar, and pitch, excluding petroleum pitch. Prev Med 5 (1976) 262-278.

11. LaFontaine M. Huiles minerales et cancers cutanes. Institut National De Recherche et de Securite, Paris 1978. (Les notes scientifiques et techniques de l'I.N.R.S. no 17).

12. Mastromatteo E. Cutting oils and squamous-cell carcinoma: Part I Incidence in a plant with a report of six cases. Br J Ind Med 12 (1955) 240-243.

13. Thony C, Thony $J$, LaFontaine $M$, Limasset JC. Hydrocarbures polycycliques aromatiques cancerogenes dans les produits petroliers preventions possibles du cancer des huiles minerales. Inserm Symp Ser 52 (1976) $165-170$.

14. Waldron HA. A brief history of scrotal cancer. $\mathrm{Br} \mathbf{J}$ Ind Med 40 (1983) 390-401.

Received for publication: 10 December 1984 